\title{
Yüksek Fırın Cürufu ile Stabilize Edilmiş Killi Bir Zeminin Yol Esnek Üstyapı Tabaka Kalınlıklarına ve Maliyetine Etkileri
}

\author{
Tacettin GEÇKIL ${ }^{1}$, Mehmet Mahmut TANYILDIZI ${ }^{2 *}$, Ekrem Serdar YILDIRAN ${ }^{3}$ \\ 1 İnönü Üniversitesi, Mühendislik Fakültesi, İnşaat Mühendisliği Bölümü, Malatya, Türkiye \\ 2 2'nci Ordu Komutanlığı, Malatya, Türkiye \\ ${ }^{3}$ Togi Metal İnş.San.Tic.Ltd.Şti., Malatya, Türkiye \\ ${ }^{1}$ tacettin.geckil@inonu.edu.tr, ${ }^{* 2}$ mmtanyildizi@ hotmail.com, ${ }^{3}$ serdaryildiran44@ gmail.com
}

\begin{abstract}
Öz: Bu çalışmada, çelik üretimi esnasında bir yan ürün olarak ortaya çıkan Yüksek Fırın Cürufu (YFC) ile stabilize edilmiş killi bir yol taban zemininin yol esnek üstyapı kalınlığına ve maliyetine etkileri araştırılmıştır. Bu amaçla, kil zemine ağırlıkça $\% 5,10,15,20$ oranlarında YFC ilave edilerek stabilize karışım numuneleri hazırlanmıştır. Hazırlanmış olan saf ve katkılı numuneler Standart Proktor, serbest basınç ve Kaliforniya Taşıma Oranı (CBR) deneylerine tabi tutularak en yüksek dayanımı veren YFC oranı belirlenmiştir. Bu oran dikkate alınarak, AASHTO 1993 yöntemi ile YFC katkılı zemin üzerine inşa edilecek yol esnek üstyapı tabaka kalınlıkları ve maliyetleri hesaplanmıştır. Deneyler neticesinde, YFC katkısı ile kil zeminin dayanımında önemli iyileșmeler olduğu ve en iyi dayanımın \%20 YFC içeren karıșımlardan elde edildiği tespit edilmiștir. AASHTO 1993 yöntemi ile yapılan hesaplamalar sonucunda, \%20 YFC içeren zeminler için belirlenen tabaka kalınlıklarının, saf killi zemine göre oldukça azaldığg görülmüştür. Her iki zemin için belirlenen tabaka kalınlıklarına göre yapılan tasarım hesabında, zemine \%20 YFC ilave edilmesinin, saf killi zemine kıyasla yol üstyapı tabaka kalınlığı \%26,67 oranında azalttığ tespit edilmiştir.
\end{abstract}

Anahtar kelimeler: Esnek üstyapı, killi zemin, yüksek firın cürufu, AASHTO metodu.

\section{Effects of a Clay Soil Stabilized by Blast Furnace Slag on Road Flexible Pavement Layer Thickness and Cost}

\begin{abstract}
In this study, the effects of a clay road subgrade stabilized by Blast Furnace Slag (BFS), which appeared as a byproduct during steel production, on road flexible pavement thickness and cost were investigated. For this purpose, stabilized mixture samples were prepared by adding $\% 5,10,15,20 \mathrm{BFS}$ to the clay soil by weight. The pure and additive samples were conducted Standard Proctor, Unconfined Compression and California Bearing Ratio (CBR) experiments and the BFS ratio was determined to provide the highest strength. Taking into account this ratio, the road flexible pavement layer thicknesses and costs to be built on BFS-additive soil were calculated with the AASHTO 1993 method. As a result of the experiments, it was determined that there were significant improvements in the strength of the clay soil with the contribution of BFS and that the best strength was obtained from mixtures containing \%20 BFS. As a result of calculations made by AASHTO 1993, it was observed that the layer thickness determined for soils containing \%20 BFS decreased considerably compared to pure clay soils. In the design calculation according to the layer thicknesses determined for both soils, it was determined that adding $20 \%$ BFS to the soil reduced the layer thickness of the road pavements by $26.67 \%$ compared to pure clay soil.
\end{abstract}

Key words: Flexible pavement, clay soil, blast furnace slag, AASHTO method.

\section{Giriş}

Günümüzde, karayolu esnek üstyapılarının inşa edileceği bölgelerde, taşıma gücü zayıf taban zeminlerine çeşitli katkı maddeleri ilave edilerek zeminlerin dayanımı iyileştirilmekte ve üstyapının sağlam bir taban zeminin üzerine oturması sağlanmaktadır. Bu amaçla, zayıf taşıma gücüne sahip zeminlerin dayanımlarını arttırmak için fiziksel, kimyasal ve mekanik olmak üzere çeşitli yöntemler kullanılarak zeminlerin dayanımları arttırılmaya çalışılmaktadır [1].

Zemin özelliklerini iyileştirmek maksadıyla çoğunlukla tercih edilen yöntem zemine katkı maddesi ilave edilerek dayanımında iyileşme sağlamaktır. Bu kapsamda kireç, çimento, uçucu kül, YFC vb. gibi katkılar, zeminlerin dayanımlarının iyileştirilmesinde sıklıkla kullanılan katkı maddeleridir. Bu katkı maddelerinin kullanılması ile, zeminlerin hacimsel stabilite, mukavemet, permeabilite (geçirgenlik), sıkışabilirlik, dayanıklılık (durabilite) gibi özelliklerinde iyileşme sağlanabildiği görülmüştür. Ayrıca, bu katkı maddelerinin maliyetlerinin

\footnotetext{
* Sorumlu yazar: mmtanyildizi@ @otmail.com. Yazarların ORCID Numaras1: ${ }^{10000-0001-8070-6836, ~}{ }^{20000-0001-5992-2665, ~}{ }^{30000-0002-}$
} 
uygun olması ve kolaylıkla temin edilebilmesi zemin iyileştirilmesinde veya stabilizasyonunda kullanılmasını tercih sebebi haline getirmiştir [2-3-4].

Killi zeminler gibi taşıma gücü zayıf olan zeminler, yol yapım çalışmalarında bulunması istenmeyen kayma mukavemeti düşük, şişme, büzülme, permeabilite ve sıvılaşma potansiyeli yüksek zeminlerdir ve bu tür zeminler genel olarak zayıf zeminler olarak adlandırılırlar. Bu yüzden, bu tip zeminle karşılaşılan yol yapım çalışmalarında katkı maddeleri kullanılarak taşıma gücü yüksek ve şişme potansiyeli göstermeyen (geoteknik özellikleri daha iyi olan) zeminler elde edilmektedir [5].

Günümüzde ilerleyen teknoloji ile birlikte sanayi atıklarının bertarafını sağlamak oldukça önem kazanmıştır. $\mathrm{Bu}$ amaçla, zemin iyileştirme ve dolgu malzemesi gibi farklı inşaat mühendisliği uygulamalarında çeşitli atık malzemelerin kullanımı oldukça yaygınlaşmıştır. Bu sayede, ülkemizde çevresel kirliliğe neden olan atık malzemelerinin geri dönüşümü sağlanmış olacağı gibi, ekonomik olarak da kazanç elde edilecektir [6].

Bu çalışma kapsamında, atık YFC'nin zayıf taşıma gücüne sahip killi bir yol taban zemininin dayanımı üzerinde etkisi araştırılmış ve araştırma sonucunda elde edilen veriler ışığında bu durum yol esnek üstyapısı maliyeti bakımından değerlendirilmiştir.

Demir-çelik üretimi sırasında bir yan ürün olarak ortaya çıkan YFC, karayolu mühendisliğinde yol kaplaması, alttemel, temel, zemin iyileştirme ve dolgu malzemesi gibi çeşitli mühendislik uygulamalarında kullanılmaktadır. YFC'nin yapısının \%95'i silika, kalsiyum, alüminyum, magnezyum ve oksijenden gibi elementlerden oluşmaktadır [6-7-8-9]. Bu özelliklere sahip bir yan ürün olarak elde edilen YFC'nin, zayıf zeminlerin dayanımlarının artıılması maksadıyla kullanılması, hem zeminin taşıma gücü, hem atıkların bertaraf edilmesi ve hem de ekonomik kazanç bakımından fayda sağlayacağı düşünülmektedir [9].

Birçok ülkede, YFC kullanılarak yapılan zemin iyileştirme çalışmalarında olumlu sonuçlar elde edilmiştir. Çalışmalarda, YFC'nin yeraltı suyundan etkilenmediği ve arazide kullanımının uygun olduğu ve YFC'nin yol stabilizasyonunda katkı malzemesi olarak kullanılabileceği görülmüştür [10].

Sivrikaya ve ark. [11], kil zeminlerin dayanımlarının artırılmasında YFC'nin kullanılabilirliğini araştırmışlardır. Araştırmacılar, iki farklı kil zemin içerisine \%5, 10, 20, 30 ve 50 oranlarında YFC ilave ederek karışım numunelerinin özelliklerini incelemişlerdir. Her iki saf kil zemin için YFC oranı arttıkça birim hacim ağırlığının da artış gösterdiği tespit edilmiştir. Benzer şekilde, kil zeminlerin plastik limit (PL) değerleri artış gösterirken, likit limit (LL) değerlerinde azalma meydana gelmiştir. Bu sonuçlar işı ğında, killerin plastisite indekslerinin (PI) de \%92-\%180 aralığında azaldığı tespit edilmiştir. PI değerlerinin azalması, YFC katkısının killi zeminlerin su hassasiyetini azalttığı sonucunu doğurmuştur.

Bilgen ve ark. [12], killi zeminlerin dayanımlarının iyileştirilmesinde YFC ve kirecin kullanılabilirliğini araştırmışlardır. Çalışmada, YFC için $\% 0$ ile $\% 7,5$, kireç için ise $\% 0$ ile $\% 5$ oranlarında karışım numuneleri hazırlanmış ve bu numunelerin özellikleri incelenmiştir. Deney sonuçlarına göre, YFC'nin tek başına plastisite üzerinde bir etkisinin olmadığı, ancak \%5 kireç ve \%3,33 YFC karışımında plastisitenin 28 den 9'a düştüğü tespit edilmiștir. YFC hem tek başına, hem de kireç ile birlikte kullanıldığında optimum su içeriğinde önemli bir değișikliğe neden olmamıştır. YFC tek başına kullanıldığında serbest basınç dayanımını yaklaşık 2 kat arttırırken, $\% 5$ kireç ve \%3,33 YFC karışımı birlikte kullanıldığında serbest basınç dayanımı 11 kat artmıştır.

Cokca ve ark. [13] YFC ve YFC-çimento karışımını, şişme özelliği gösteren zeminlerin dayanımı üzerindeki etkileri için araștırmışlardır. Çalışmada, zemin numunelerine \%5 ile \%25 oranlarında YFC ve YFC-çimento karışımı ilave edilmiştir. Bu katkıların dane boyu dağılımı, kıvam limitleri, şişme hızı ve şişme oranı üzerindeki etkileri araştırılmıştır. Deneyler sonucunda, katkı miktarı arttıkça zeminlerin plastisite indeksi ve şişme yüzdesi azalırken, özgül ağırlığı artış göstermiştir. Çalışmanın sonucunda, hem çevresel etkiler hem de şişme yüzdesi göz önüne alındığında \%15YFC-çimento karışımının en optimum seçenek olduğu tespit edilmiştir.

Bu çalışmada, daha önce gerçekleştirilen çalışmalardan farklı olarak, YFC ile dayanımı artırılan taşıma gücü zayıf killi bir yol taban zemininin, yol esnek üstyapı tabaka kalınlıklarına ve maliyetlerine etkisi araştırılmıştır. Bu amaçla, dayanımları artırılmış zemin numuneleri üzerinde sıkıştırma, serbest basınç, CBR deneyleri yapılmış ve AASHTO 1993 tasarım yöntemi yardımıyla saf kil ve YFC katkılı zeminde esnek üstyapı tabaka kalınlıkları belirlenerek güncel maliyetleri hesaplanmıştır.

\section{Materyal ve Deneysel Çalışmalar}

Çalışma kapsamında, yol taban zemini olarak kullanılan kil malzeme Malatya Kiltepe bölgesinden temin edilmiştir. Kil malzemesinin mühendislik özellikleri TS 1900-1 standardına göre belirlenmiş ve Tablo 1'de verilmiştir. 
Tablo 1. Kil zemininin fiziksel özellikleri

\begin{tabular}{lcc}
\hline \multicolumn{1}{c}{ Parametre } & Birimi & Değeri \\
\hline Dane birim hacim ağırlığı $\left(\gamma_{\mathrm{s}}\right)$ & $\mathrm{g} / \mathrm{cm}^{3}$ & 2,680 \\
Maksimum kuru birim hacim ağırlı̆̆ $\left(\mathrm{g}_{\mathrm{kmax}}\right)$ & $\mathrm{g} / \mathrm{cm}^{3}$ & 1,450 \\
Optimum su içeriği $\left(\mathrm{w}_{\mathrm{opt}}\right)$ & $\%$ & 27 \\
Likit limit (LL) & $\%$ & 61 \\
Plastik limit (PL) & $\%$ & 29 \\
Plastisite indeksi (PI) & - & 32 \\
Birleştirilmiş zemin sınıflandırma sistemi (USCS) & - & $\mathrm{CH}$ \\
AASHTO sınıflandırma sistemi & & $\mathrm{A}-7-6$ \\
\hline
\end{tabular}

Karayolları Teknik Şartnamesi (KTŞ) verilerine göre, AASHTO sınıflandırma sisteminde A5, A6, A7, A-26, A-2-7 veya birleştirilmiş zemin sınıflandırma sistemine göre $\mathrm{CH}, \mathrm{CL}, \mathrm{MH}, \mathrm{ML}, \mathrm{GC}, \mathrm{SC}$ sınıfina giren plastisite indeksi 10'dan büyük ( $\mathrm{PI} \geq 10)$ veya Kaliforniya taşıma oranı (Yaş CBR \%) $<10$ veya CBR şişme yüzdesi $\% \geq 3$ olan ve en az $\% 25$ 'i $75 \mu \mathrm{m}$ elekten geçen zemin/malzemeler için stabilizasyon-iyileştirme yapılması öngörülmüştür. Çalışma kapsamında temin edilen kil zeminin sınıfi; Birleştirilmiş Zemin Sınıflandırma Sistemi (USCS) verilerine göre yüksek plastisiteli kil (CH), AASHTO sınıflandırma sistemi verilerine göre A-7-6 (en kötü zemin), kil zeminin PI $=32 \geq 10$ olduğundan dolayı KTŞ'ye uygun olarak taşıma gücü zayıf kil zemin stabilize edilerek dayanımı artııılmıștır [14].

Kil zeminin dayanımının iyileştirilmesi amacıyla kullanılan ve özgül ağırlığı 2,750 g/ $\mathrm{cm}^{3}$ olan YFC ise Karabük ili Karçimsa tesisinden temin edilmiş ve kimyasal özellikleri Tablo 2'de gösterilmiş̧ir.

Tablo 2. Yüksek firın cürufunun (YFC) kimyasal özellikleri

\begin{tabular}{ccccccccccccc}
\hline $\begin{array}{c}\text { Kimyasal } \\
\text { Bileşen }\end{array}$ & $\mathrm{SiO}_{2}$ & $\mathrm{Al}_{2} \mathrm{O}_{3}$ & $\mathrm{Fe}_{2} \mathrm{O}_{3}$ & $\mathrm{CaO}$ & $\mathrm{MgO}$ & $\mathrm{SO}_{3}$ & $\mathrm{~S}$ & $\mathrm{Na}_{2} \mathrm{O}$ & $\mathrm{K}_{2} \mathrm{O}$ & $\mathrm{TiO}_{2}$ & $\mathrm{Mn}_{2} \mathrm{O}_{3}$ & $\mathrm{CI}$ \\
$\begin{array}{c}\text { Ăğrrlıkça } \\
\text { İçerik } \\
(\%)\end{array}$ & 32,47 & 9,94 & 1,25 & 32,45 & 9,31 & 0,82 & 0,33 & 0,31 & 0,85 & 1,16 & 3,51 & 0,015 \\
\hline
\end{tabular}

Çalışma kapsamında, kil-YFC karışım numuneleri hazırlanmadan önce her iki malzeme 24 saat süresince $105 \pm 5{ }^{\circ} \mathrm{C}$ 'lik etüvde kurutulmuştur. Daha sonra, kil zemin içerisine literatürde yapılmış olan önceki çalışmalar [11-12-13] dikkate alınarak ağırlıkça $\% 5,10,15$ ve 20 oranlarında YFC ilave edilerek stabilize karışımlar hazırlanmıștır.

Çalışmanın tamamında, saf kil ve stabilize karışımlar sırasıyla Kil, \%5 YFC, \%10 YFC, \%15 YFC ve \%20 YFC olarak adlandırılmıştır.

Çalışmada, saf kil ve stabilize karışım numunelerinden üçer adet hazırlanarak, numuneler üzerinde TS 19001'e uygun olarak Standart Proktor deneyi gerçekleştirilmiştir. Stabilize numuneler optimum su oranı tayini için deneye tabi tutulurken, YFC'nin karışımdaki puzolanik reaktivitesini arttırmak ve zemin ile arasında iyi bir aderans temin etmek amaciyla [15] su yerine Sodyum Hidroksit (NaOH) solisyonu eklenmiştir.

Sikıştırma çalışmaları sonucunda, numunelerin Standart Proktor deneyleri sonucunda elde edilen Kuru Yoğunluk-Su İçeriği grafikleri Şekil 1'de gösterilmiştir. 


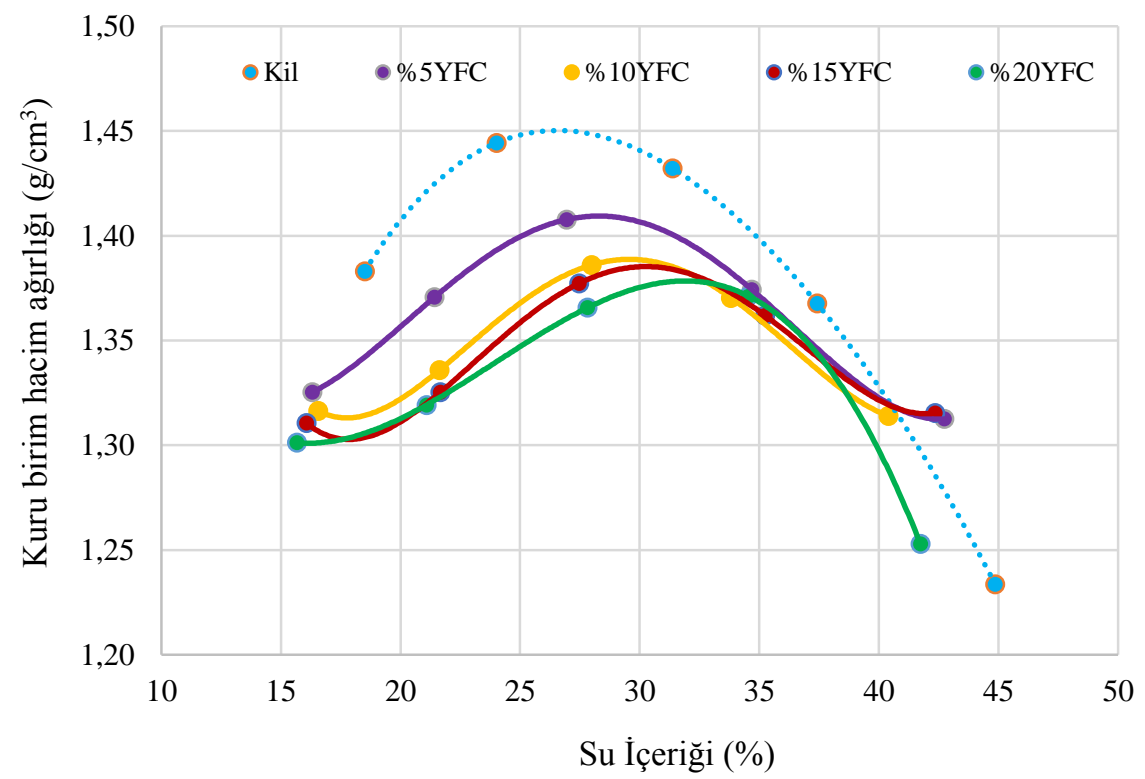

Şekil 1. Numunelerin kuru yoğunluk $\left(\mathrm{g}_{\mathrm{k}}\right)$ - su içeriği (\%) grafikleri

Şekil 1 dikkate alındığında, YFC miktarındaki artış ile orantılı olarak numunelerin maksimum kuru yoğunluklarında azalma, optimum su muhtevasında ise artış meydana geldiği görülmektedir. Su muhtevasındaki artışın ve kuru yoğunlukta meydana gelen azalmanın, YFC'nin yüksek su emme potansiyelinden ve ince daneli olmasından kaynaklandığı [15] düşünülmektedir.

Serbest basınç deneyi genellikle suya doygun normal konsolide killi zeminlerde kayma direncinin belirlenmesinde kullanılan bir deney olup, deney sonucunda elde edilen Mohr dairesinden zemine ait kayma direnci hesaplanabilmektedir. Deneyde tercihen $38 \mathrm{~mm}$ çapında ve $76 \mathrm{~mm}$ boyunda silindirik kohezyonlu zemin numuneleri kullanılmaktadır. Bu deney, gerilme kontrollü ve deformasyon kontrollü olmak üzere iki şekilde yapılmakla birlikte, yaygın olarak birim boy kısalması kontrollü olanı tercih edilmektedir. Deney, numunenin deney süresince su içeriğinde değişiklikler olabileceğinden dolayı 5-10 dk içerisinde tamamlanmalı ve birim boy kısalması $\% 0,5 / \mathrm{dk}-\% 2 / \mathrm{dk}$ olmalıdır. Deneye, numunenin taşıdığı yük azalmaya başladığı zaman ya da boy kısalmasının \%20'ye ulaşmasından sonra son verilebilir. Bu deneyde eksenel gerilmenin en büyük değeri serbest basınç dayanımını $\left(\mathrm{q}_{\mathrm{u}}\right)$ verir. Drenajsız kayma mukavemeti ise; $\tau=\mathrm{c}_{\mathrm{u}}=\mathrm{q}_{\mathrm{u}} / 2$ bağıntısı ile elde edilir. Deney çalışmaları kapsamında, Standart Proktor deneyi sonucunda bulunan optimum su içerikleri dikkate alınarak, serbest basınç ve CBR deneylerine tabi tutmak amacıyla karışım numuneleri hazırlanmıştır. Öncelikle, hazırlanmış olan bütün numuneler 28 günlük kür süresine tabi tutulmuş ve bu süre sonunda serbest basınç deneyine maruz bırakılmıştır. Karışım numunelerinin 28 günlük kür süresi sonucunda elde edilen Gerilme-Şekil değiştirme grafikleri Şekil 2'de verilmiştir. 


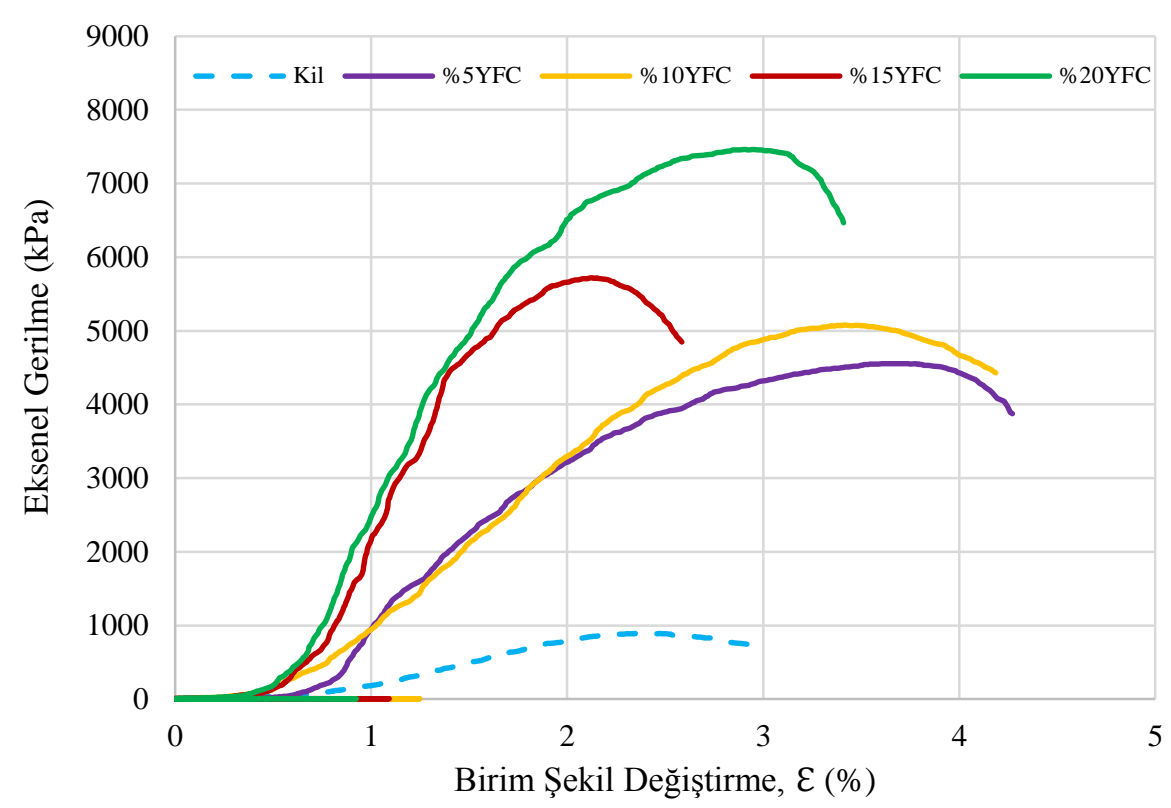

Şekil 2. Saf ve YFC katkılı numunelerin serbest basınç deneyi sonuçları

Şekil 2'de görüldüğü üzere, hazırlanan karışımlar içerisinden maksimum serbest basınç dayanımının \%20YFC katkılı kil numunelere ait olduğu tespit edilmiştir. 28 günlük kür süresi sonunda $\% 20$ YFC katkısı ile stabilize kilin serbest basınç dayanımında önemli miktarda artı̧ olduğu gözlemlenmiştir. Bu durumun, YFC'nin puzolanik bir malzeme olması ve puzolanik malzemelerin geç mukavemet kazanmasından kaynaklandığı değerlendirilmektedir.

Ancak, YFC kullanılarak yapılan önceki çalışmalar dikkate alındığında maksimum dayanımı veren oranların birbirinden farklılık gösterdiği görülmektedir [11-12-13]. Yapılan incelemeler neticesinde bu farklılı̆̆ın kullanılan killerin ve YFC'nin yapısal farklılıklarından ve puzolanik reaksiyonu artırmak için kullanılan çözeltilerin cins ve miktarından kaynaklandığı görülmektedir.

Serbest Basınç deneyleri sonucunda, en efektif katkı oranı $\% 20$ olarak tespit edildikten sonra, saf ve stabilize karışım numuneleri CBR deneyine tabi tutulmuştur. Bu amaçla, saf kil ve \%20 YFC içeren karışım numuneleri hazırlanarak bu numuneler 28 günlük kür süresine tabi tutulmuştur. Çalışmada, her bir deney için ikişer adet numune hazırlanmıştır. CBR deneyine tabi tutulan saf kil ve \%20 YFC katkılı karışım numunelerine ait CBR deney sonuçları Tablo 3 ’te gösterilmiştir.

Tablo 3. Saf kil ve \%20 YFC katkılı karışım numunelerinin 28 günlük CBR değerleri

\begin{tabular}{cccc}
\hline Numune & Kür Süresi & CBR (2,5 mm), (\%) & CBR (5 mm), (\%) \\
\hline Saf Kil & 28 günlük & 32 & 26,40 \\
Saf Kil+\%20 YFC & & 416,04 & 315,63 \\
\hline
\end{tabular}

Tablo 3'te görüldüğü üzere deneyler sonucunda; 28 günlük küre tabi tutulmuş saf kilin 2,5 ve 5 mm'lik deplasmanlarına ait düzeltilmiş CBR değerleri sırasıyla \%32 ve \%26,4; \%20YFC katkılı kil zemininin aynı deplasmanlara karş̧lık gelen düzeltilmiş CBR değerleri sırasıyla $\% 416,04$ ve $\% 315,63$ olarak belirlenmiş̧ir. Bu sonuçlar, YFC'nin kil zeminin deformasyonlara karşı direnci üzerinde olumlu bir etkiye sahip olduğunu göstermektedir.

\section{AASHTO Metodu ile Esnek Üstyapıda Taşıma Gücünün Analitik İncelenmesi}

Karayolu üstyapıları, esnek ve rijit üstyapılar olmak üzere genellikle iki şekilde tasarlanmaktadır. Bağlayıcı malzeme olarak asfalt çimentosunun kullanıldığı esnek üstyapılar genel olarak asfalt betonu kaplama, temel ve alt 
temel tabakalarından oluşmaktadır. Portland çimentosu kullanılarak inşa edilen kaplama tabakasından oluşan üstyapılar ise rijit üstyapı olarak isimlendirilir ve bu yapılar klasik olarak temel ve beton plak kaplamadan oluşur [16]. Tipik bir esnek üstyapı kesiti aşağıda Şekil 3 'te verilmiştir.

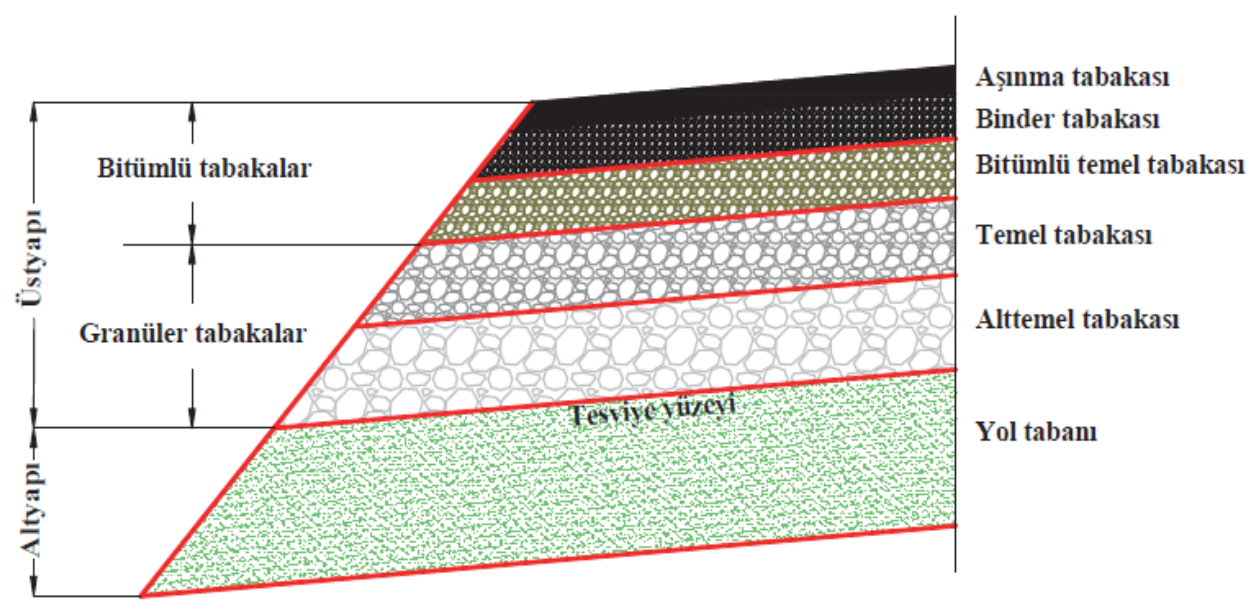

Şekil 3. Esnek bir üstyapının kesit görünümü [16].

Karayolu esnek üstyapı tasarımında hedef, projelendirilen yolun tasarım ömrü süresince tekerrür edecek olan trafiği çatlamalara ve deformasyonlara maruz bırakmadan emniyetli bir şekilde taşıyabilecek üstyapı tabaka kalınlıklarının belirlenmesi ve üstyapı tabakalarını oluşturacak malzemelerin özelliklerinin belirlenmesidir. Bu kapsamda, AASHTO 1993 üstyapı tabaka kalınlıklarının hesabında Denklem 1 ile verilmiş olan ampirik denklem kullanılmaktadır. $\mathrm{Bu}$ denklem kullanılarak esnek üstyapı tasarımı için Üstyapı Sayısı (SN) değeri hesaplanmaktadir [17].

$$
\begin{aligned}
& \log T_{8,2}=Z_{R} \times S_{0}+9,36 \times \log _{10}(\mathrm{SN}+1)-0,20+\frac{\log (\Delta \mathrm{PSI} /(4,2-1,5))}{0,40+\left[1094 /(\mathrm{SN}+1)^{5,19}\right]} \\
& +2,32 \times \log _{10}\left(\mathrm{M}_{\mathrm{R}}\right)-8,07
\end{aligned}
$$

Burada;

$\mathrm{T}_{8,2} \quad: \mathrm{P}_{\mathrm{t}}{ }^{\prime}$ ye erişinceye kadar tekerrür edecek standart dingil (8,2 ton) sayıs1

$\mathrm{M}_{\mathrm{R}} \quad$ : Taban zemini esneklik modülü, psi $\left(6,8950 \times 10^{3} \mathrm{~Pa}\right)$

$\mathrm{S}_{0} \quad$ : Toplam standart sapma

$\mathrm{Z}_{\mathrm{R}} \quad$ : Güvenilirliğin standart normal sapma değeri

SN : Üstyapı sayısı (inç)

$\mathrm{P}_{0} \quad$ : Yolun ilk servis kabiliyeti

$\mathrm{P}_{\mathrm{t}} \quad$ : Yolun son servis kabiliyeti

$\triangle$ PSI : Servis kabiliyetindeki azalma miktarı $\left(\mathrm{P}_{0}-\mathrm{P}_{\mathrm{t}}\right)$

SN değeri Denklem 1 ile bulunduktan sonra Tablo 4'de verilen tabaka katsayılarına göre gerekli esnek üstyap1 tabaka kalınlıkları Denklem 2 ile hesaplanmaktadır [17].

$\mathrm{SN}=\mathrm{a}_{1} \times \mathrm{D}_{1}+\mathrm{a}_{2} \times \mathrm{D}_{2} \times \mathrm{M}_{2}+\mathrm{a}_{3} \times \mathrm{D}_{3} \times \mathrm{M}_{3} \ldots \ldots \ldots \ldots \mathrm{a}_{\mathrm{i}} \times \mathrm{D}_{\mathrm{i}}$

Bu denklemde; $\mathrm{a}_{1}, \mathrm{a}_{2}, \mathrm{a}_{3}$ sırası ile kaplama, temel ve alttemel tabakalarının izafi mukavemet katsayıları, $\mathrm{D}_{1}$, $\mathrm{D}_{2}, \mathrm{D}_{3}$ kaplama, temel, alttemel tabaka kalınlıkları, $\mathrm{M}_{2}, \mathrm{M}_{3}$ ise temel ve alttemel tabakası drenaj katsayılarını göstermektedir. Esnek üstyapı tabaka kalınlıklarının hesaplanmasında drenaj katsayıları 1,00 olarak alınmıştır. 
Tablo 4. AASHTO tabaka katsayıları [17].

\begin{tabular}{lccc}
\hline \multicolumn{1}{c}{ Tabaka Cinsi } & $\begin{array}{c}\text { Marshall Stabilitesi } \\
(\mathbf{k g})\end{array}$ & CBR (\%) & $\begin{array}{c}\text { İzafi Mukavemet } \\
\text { Katsayıs (a) }\end{array}$ \\
\hline Kaplama Tabakası & $\geq 900$ & - & \\
Aşımma & $\geq 750$ & - & 0,42 \\
Binder & $\geq 600$ & - & 0,40 \\
Bitümlü Temel & & & 0,36 \\
& - & $\geq 100$ & \\
Temel Tabakası & - & $\geq 120$ & 0,14 \\
Granüler Temel & & & 0,15 \\
Plentmiks Temel & - & $\geq 30$ & \\
Alttemel Tabakası & - & $\geq 50$ & 0,11 \\
Kum-Çakıl Alttemel & - & & \\
Kırmataş Alttemel & & & \\
\hline
\end{tabular}

Esnek üstyapı tabaka kalınlıkları belirlendikten sonra Şekil 4'te verilen $\mathrm{SN}^{*}$ değerleri hesaplanarak tabaka kalınlıklarının kontrolü yapılmıştır.

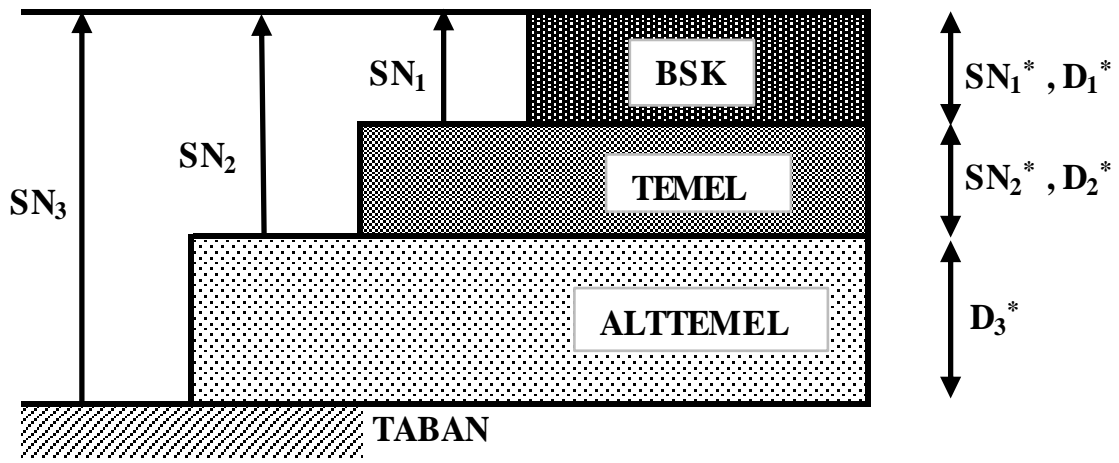

Şekil 4. Esnek üstyapıda üstyapı sayıları [14].

$\mathrm{SN}_{1}$ : Temel tabakası üzerine gereken $\mathrm{SN}$

$\mathrm{SN}_{2}$ : Alttemel tabakası üzerine gereken $\mathrm{SN}$

$\mathrm{SN}_{3}$ : Taban üzerine gereken $\mathrm{SN}$

* : Kullanılan malzemeye göre mevcut değerleri göstermektedir.

Çalışmada, YFC'nin esnek üstyapı üzerindeki etkilerini belirlemek amacıyla en uygun dayanımı veren karışım oranı ve 28 günlük kür süresi dikkate alınarak AASHTO 1993 yöntemi ile esnek üstyapı tasarımı yapılmıştır.

\subsection{AASHTO Metodu ile Esnek Üstyapıda Saf ve \%20YFC Katkılı Kil Zeminin Taban Zemini Taşıma Gücünün Analitik İncelenmesi}

Esnek üstyapı tasarımı için, \%20 YFC katkılı kil zemininin 28 günlük kür süresi sonundaki CBR değerleri esas alınmıştır. Saf ve \%20YFC katkılı kil zeminlerin 28 günlük kür sonunda elde edilen CBR değerleri olan \%32 ve $\% 416,04$ oranları sırasıyla kullanılarak hesaplamalar yapılmıştır. Bunun için, öncelikle AASHTO yöntemi ile üstyapısı dizayn edilecek yolun taban zemininin esneklik modülü $\left(\mathrm{M}_{\mathrm{R}}\right)$ değerinin hesaplanması gerekir.

Zemine ait $M_{R}$ ve $C B R$ değerleri arasında $M_{R}=1500 \times C B R$ bağıntısı mevcut olup, zemine ait $C B R$ değerinin bilinmesi durumunda $\mathrm{M}_{\mathrm{R}}$ değeri yaklaşık olarak hesaplanabilmektedir [18].

Buna göre, saf ve \%20 YFC katkılı kil zeminler için $\mathrm{M}_{\mathrm{R}}$ değerleri sırasıyla, kil zemin için 48.000 psi (330948350,07 Pa) ve \%20 YFC katkılı kil zemin için 624.060 psi (4302742236,4 Pa) olarak bulunmuștur. Tablo 
5'teki veriler kullanılarak Denklem 1 bağıntı yardımı ile saf ve \%20 YFC katkılı kil zeminler için taban üzerine gereken $\mathrm{SN}_{3}$ (taban üzerine gereken $\left.\mathrm{SN}\right)$ değerleri sırasıyla 5,71 inç $(14,50 \mathrm{~cm})$ ve 2,24 inç $(5,69 \mathrm{~cm})$ olarak hesaplanmıştır. Esnek kaplamaların hesaplamalarında kullanılan diğer ortak değerler ise Tablo 5 'te verilmiştir.

Tablo 5. Esnek üstyapı kaplama hesabında kullanılan parametreler

\begin{tabular}{lc}
\hline \multicolumn{1}{c}{ Parametreler } & Seçilen Değerler \\
\hline Eşdeğer standart dingil yükü tekerrür sayısı, $\mathrm{T}_{8,2}$ & 30.000 .000 \\
Toplam standart sapma, $\mathrm{S}_{0}$ & 0,45 \\
Yolun ilk servis kabiliyeti, $\mathrm{P}_{0}$ & 4,20 \\
Yolun son servis kabiliyeti, $\mathrm{P}_{\mathrm{t}}$ (Otoyollar, devlet yolları için & 2,50 \\
2,5) & 1,70 \\
Servis kabiliyeti indeksi, $\Delta \mathrm{PSI}$ & $-1,037$ \\
$\begin{array}{l}\text { Güvenilirliğin standart normal sapması, } \mathrm{Z}_{\mathrm{R}} \text { (Devlet yolu } \\
\mathrm{R}=\% 85)\end{array}$ & \\
\hline
\end{tabular}

\subsection{Saf ve \%20 YFC Katkılı Zemin İçin Esnek Üstyapı Tabaka Kalınlıklarının Belirlenmesi ve Bu Kalınlıklarının Kontrolü}

Denklem 1 bağıntısı ile saf killi zemin için $\mathrm{SN}_{3}$ değerleri 5,71 inç $(14,50 \mathrm{~cm})$ ve \%20YFC katkılı zemin için 2,24 inç $(5,69 \mathrm{~cm})$ olarak hesaplandıktan sonra seçilen esnek üstyapı tabaka kalınlıkları Tablo 6'da, \%20 YFC katkılı zemin için seçilen tabaka kalınlıkları Tablo 7'de gösterilmiştir.

Tablo 6. Saf kil zemin için önerilen tabaka kalınlıkları

\begin{tabular}{ccc}
\hline Tabaka Adı & $\begin{array}{c}\text { Önerilen Kalınlık } \\
\left(\mathbf{D}_{\mathbf{i}}\right),(\mathbf{c m})\end{array}$ & $\begin{array}{c}\text { İzafi Mukavemet } \\
\text { Katsayısı (ai })\end{array}$ \\
\hline Aşınma & 5 & 0,42 \\
Binder & 10 & 0,40 \\
Bitümlü Temel & 12 & 0,36 \\
Plent-miks Temel & 15 & 0,15 \\
Kırmataş Alttemel & 15 & 0,13 \\
\hline
\end{tabular}

Tablo 7. \%20YFC katkılı zemin için önerilen tabaka kalınlıkları

\begin{tabular}{ccc}
\hline Tabaka Adı & $\begin{array}{c}\text { Önerilen Kalınlık } \\
\left(\mathbf{D}_{\mathbf{i}}\right),(\mathbf{c m})\end{array}$ & $\begin{array}{c}\text { İzafi Mukavemet } \\
\text { Katsayısı }\left(\mathbf{a}_{\mathbf{i}}\right)\end{array}$ \\
\hline Aşınma & 5 & 0,42 \\
Binder & 8 & 0,40 \\
Bitümlü Temel & 12 & 0,36 \\
Plent-miks Temel & 20 & 0,15 \\
Kırmataş Alttemel & - & - \\
\hline
\end{tabular}


Saf ve \%20 YFC katkılı kil zemin için belirlenen üstyapı tabaka kalınlıkları toplamı sırasıyla $57 \mathrm{~cm}$ ve $45 \mathrm{~cm}$ olarak belirlenmiştir. \%20 YFC içeren killi zeminler için tabaka kalınlığı saf zemine kıyasla \%26,67 oranında azalma gösterdiği tespit edilmiştir.

Seçilen tabaka kalınlıklarının kontrolünün yapılabilmesi maksadıyla, Tablo 5'den plentmix kırmataş temel için $\mathrm{CBR}=120$ ve kırmataş alt temel için $\mathrm{CBR}=50$ olarak seçilerek, plentmix kırmataş temel için $\mathrm{M}_{\mathrm{R}}=180.000$ psi ve kum çakıl alt temel için $\mathrm{M}_{\mathrm{R}}=75.000$ psi olarak hesaplanır. $\mathrm{M}_{\mathrm{R}}$ değeri hesaplandıktan sonra, bu tabakalar üstünde gerekli SN değerleri Denklem 1 bağıntı yardımı ile plentmix kırmataş temel için $\mathrm{SN}_{1}=3,62$ inç $(9,19 \mathrm{~cm})$, kırmataş alt temel için $\mathrm{SN}_{2}=4,95$ inç $(12,57 \mathrm{~cm})$ olarak hesaplanmıştır.

Tablo 8'de saf kil zemin, Tablo 9'da \%20 YFC katkılı zemin için hesaplanan esnek üstyapı tabaka kalınlıkları kontrolü verilmiştir.

Tablo 8 ve Tablo 9'da ki hesaplamalarda, a 1 , a 2, a a , a a , as sırası ile aşınma, binder, bitümlü temel, temel ve alt temel tabakalarının izafi mukavemet katsayıları, $\mathrm{D}_{1}, \mathrm{D}_{2}, \mathrm{D}_{3}, \mathrm{D}_{4}, \mathrm{D}_{5}$ aşınma, binder, bitümlü temel, temel ve alt temel tabaka kalınlıklarını göstermektedir.

Tablo 8. Saf kil zemin için esnek üstyapı tabaka kalınlıklarının kontrolü

\begin{tabular}{|c|c|c|c|c|c|c|c|c|c|c|c|}
\hline $\begin{array}{c}D_{1} \\
(\mathbf{c m})\end{array}$ & $\mathbf{a}_{1}$ & $\begin{array}{c}\mathbf{D}_{2} \\
(\mathbf{c m})\end{array}$ & $\mathbf{a}_{2}$ & $\begin{array}{c}\mathrm{D}_{3} \\
(\mathrm{~cm})\end{array}$ & $\mathbf{a} 3$ & $\begin{array}{c}\mathrm{D}_{4} \\
(\mathrm{~cm})\end{array}$ & $\mathbf{A}_{4}$ & $\begin{array}{c}\text { D5 }_{5} \\
(\mathbf{c m})\end{array}$ & A5 & $\begin{aligned} & \mathbf{S N}^{*} \\
= & \mathbf{a}_{\mathbf{i}} \times \mathbf{D}_{\mathbf{i}}\end{aligned}$ & Açıklamalar \\
\hline 5 & 0,42 & 10 & 0,40 & 12 & 0,36 & - & - & - & - & $\mathrm{SN}_{1}{ }^{*}=10,42$ & $\begin{array}{l}\text { Plentmix kirmataş } \\
\text { temel için } \\
\mathrm{SN}_{1}{ }^{*}>\mathrm{SN}_{1} \\
(10,42>9,19) \\
\text { Uygun. }\end{array}$ \\
\hline \multicolumn{12}{|c|}{$\begin{array}{c}\mathrm{D}_{4}{ }^{*}=\left(\mathrm{SN}_{2}-\mathrm{SN}_{1}{ }^{*}\right) / \mathrm{a}_{4}=(12,57-10,42) / 0,15=14,33 \mathrm{~cm}, \text { Seçilen } \mathrm{D}_{4}=15 \mathrm{~cm} \\
\mathrm{SN}_{2}{ }^{*}=15 \times 0,15=2,25 \\
\mathrm{SN}_{1}{ }^{*}+\mathrm{SN}_{2}{ }^{*}=10,42+2,25=12,67 \geq 12,57\left(\mathrm{SN}_{2}\right)\end{array}$} \\
\hline \multicolumn{12}{|c|}{$\begin{array}{c}\text { Saf kil zemin için; } \mathrm{D}_{5} * \geq\left(\mathrm{SN}_{3}-(\mathrm{SN} 1 *+\mathrm{SN} 2 *)\right) / \mathrm{a}_{5} \\
\mathrm{D}_{5} * \geq(14,50-(10,42+2,25)) / 0,13 \\
\mathrm{D}_{5} * 14,07, \text { seçilen } \mathrm{D}_{5}=15 \mathrm{~cm} \\
\left(\mathrm{SN}_{1}{ }^{*}+\mathrm{SN}_{2}{ }^{*}\right)+(15 \times 0,13)=12,67+1,95=14,62 \geq 14,50\end{array}$} \\
\hline
\end{tabular}

Tablo 9. \%20YFC katkılı zemin için esnek üstyapı tabaka kalınlıkları kontrolü

\begin{tabular}{|c|c|c|c|c|c|c|c|c|c|c|c|}
\hline $\begin{array}{c}D_{1} \\
(\mathbf{c m})\end{array}$ & a1 & $\begin{array}{c}\mathrm{D}_{2} \\
(\mathrm{~cm})\end{array}$ & a2 & $\begin{array}{c}\mathrm{D}_{3} \\
(\mathbf{c m})\end{array}$ & a3 & $\begin{array}{c}\mathrm{D}_{4} \\
(\mathrm{~cm})\end{array}$ & $\mathbf{A}_{4}$ & $\begin{array}{c}\mathrm{D}_{5} \\
(\mathrm{~cm})\end{array}$ & A5 & $\begin{aligned} & \mathbf{S N}^{*} \\
= & \mathbf{a}_{\mathbf{i}} \times \mathbf{D}_{\mathbf{i}}\end{aligned}$ & Açıklamalar \\
\hline 5 & 0,42 & 8 & 0,40 & 12 & 0,36 & - & - & - & - & $\mathrm{SN}_{1}{ }^{*}=9,62$ & $\begin{array}{l}\text { Plentmix kırmataş } \\
\text { temel için } \mathrm{SN}_{1}{ }^{*}>\mathrm{SN}_{1} \\
(9,62>9,19) \text { Uygun. }\end{array}$ \\
\hline \multicolumn{12}{|c|}{$\begin{array}{c}\mathrm{D}_{4}{ }^{*}=\left(\mathrm{SN}_{2}-\mathrm{SN}_{1}{ }^{*}\right) / \mathrm{a} 4=(12,57-9,62) / 0,15=19,66 \mathrm{~cm}, \text { Seçilen } \mathrm{D}_{4}=20 \mathrm{~cm} \\
\mathrm{SN}_{2}{ }^{*}=20 \times 0,15=3,00 \\
\mathrm{SN}_{1}{ }^{*}+\mathrm{SN}_{2}{ }^{*}=9,62+3,00=12,62 \geq 12,57\left(\mathrm{SN}_{2}\right)\end{array}$} \\
\hline \multicolumn{12}{|c|}{$\begin{array}{c}\text { \%20YFC katk1l zemin kil zemin için; } \mathrm{D}_{5} * \geq\left(\mathrm{SN}_{3}-\left(\mathrm{SN}_{1} *+\mathrm{SN}_{2} *\right)\right) / \mathrm{a}_{5} \\
\mathrm{D}_{5}{ }^{*} \geq 0, \mathrm{D}_{5}=0 \text { (alt temel yap1lmayacaktır) } \\
\left(\mathrm{SN}_{1}{ }^{*}+\mathrm{SN}_{2}{ }^{*}\right)+(0 \times 0,13)=12,62+0=12,62 \geq 5,69\left(\mathrm{SN}_{3}\right)\end{array}$} \\
\hline
\end{tabular}




\subsection{Saf ve \%20 YFC Katkılı Kil Zeminler İçin Ekonomik Analiz}

Çalışmada, YFC ile iyileştirilmiş kil zeminin karayolu esnek üstyapı maliyetleri üzerindeki etkisi, Karayolları Genel Müdürlüğü (KGM) verileri esas alınarak değerlendirilmiştir.

KGM tarafından yayınlanmıș olan birim fiyat cetvellerinde, alt temel ve temel tabakaları için birim ağırlık (ton) ve birim hacim $\left(\mathrm{m}^{3}\right)$ maliyetleri; bitümlü temel, binder ve aşınma tabakaları için birim alan $\left(\mathrm{m}^{2}\right)$ maliyetleri yayınlanmıştır. Çalışmada, karayolu üstyapılarının ekonomik analizi için 2019 yılı KGM birim fiyatları poz numarası kullanılmıştır. Bu kapsamda, Tablo 10'da saf killi zemin için analiz kapsamında kullanılacak birim maliyetler verilmiştir [19].

Tablo 10. Saf killi zemin için tabaka cinslerine göre birim maliyetler

\begin{tabular}{|c|c|c|c|}
\hline Poz Numarası & Tanımı ve Birimi & $\begin{array}{l}\text { Birim } \\
\text { Fiyatı (TL) }\end{array}$ & $\begin{array}{c}\mathbf{m}^{2} / \mathbf{c m} \\
\text { Maliyeti (TL) }\end{array}$ \\
\hline KGM/6405/S-M & $\begin{array}{l}5 \mathrm{~cm} \text { sıkışmış kalınlıkta } 1 \mathrm{~m}^{2} \text { asfalt betonu aşınma } \\
\text { tabakası yapılması, }\left(\mathrm{m}^{2}\right)\end{array}$ & 13,06 & 2,61 \\
\hline KGM/6320 & $\begin{array}{l}\text { Asfalt betonu binder tabakası yapılması (kırılmış } \\
\text { ve elenmiş ocak taşı ile) (ton) Not: Kaplama } \\
\text { yoğunluğu } 2,40 \mathrm{~g} / \mathrm{cm}^{3}\end{array}$ & 83,78 & 2,02 \\
\hline KGM/6212-A & $\begin{array}{l}12 \mathrm{~cm} \text { sıkışmış kalınlıkta } 1 \mathrm{~m}^{2} \text { asfalt betonu } \\
\text { bitümlü sıcak temel tabakası yapılması }\left(\mathrm{m}^{2}\right)\end{array}$ & 21,93 & 1,83 \\
\hline KGM/6100/3 & $\begin{array}{l}\text { Plentmix temel yapılması (kırılmış ve elenmiş ocak } \\
\text { taşı ile) (ton) Not: Kaplama yoğunluğu } 2,40 \mathrm{~g} / \mathrm{cm}^{3}\end{array}$ & 40,49 & 0,97 \\
\hline KGM/6000 & $\begin{array}{l}\text { Ocak taşından konkasörle kırılmış ve elenmiş } \\
\text { malzeme ile alt temel yapılması }\left(\mathrm{m}^{3}\right)\end{array}$ & 41,68 & 0,42 \\
\hline
\end{tabular}

Saf killi zemin için tabaka cinslerine göre birim maliyetin hesaplanmasında, kırmataş alt temel tabakası 15 $\mathrm{cm}$, granüler temel tabakası $15 \mathrm{~cm}$, bitümlü temel tabakası $12 \mathrm{~cm}$, binder tabakası (asfalt betonu) $10 \mathrm{~cm}$ ve aşınma tabakası (asfalt betonu) $5 \mathrm{~cm}$ olarak hesaplanmış Tablo 6'da gösterilmişti.

Esnek yol kaplamasının maliyet hesabında; her bir tabakanın maliyeti, Tablo 10'da verilen birim fiyatların, tabakanın kendi kalınlığına bölünerek " $\mathrm{m}^{2} / \mathrm{cm}$ " cinsinden hesaplanarak elde edilmiş ve bunların toplamı ile üstyapı birim maliyeti belirlenmiştir. Bu hesaplamalara göre, esnek yol üstyapı kalınlığının $\mathrm{m}^{2} / \mathrm{cm}$ cinsinden birim maliyeti toplam 7,85 TL olarak elde edilmiştir.

Benzer şekilde, \%20 YFC katkılı kil zemin için tabaka cinslerine göre birim maliyetin hesaplanmasında, granüler temel tabakası $20 \mathrm{~cm}$, bitümlü temel tabakas $12 \mathrm{~cm}$, binder tabakası $8 \mathrm{~cm}$ ve aşınma tabakası (asfalt betonu) $5 \mathrm{~cm}$ olarak hesaplanmış ve Tablo 8 'de gösterilmiştir.

Tablo 11'de \%20 YFC katkılı kil zemine ait analiz kapsamında kullanılacak birim maliyetler verilmiştir [19]. 
Tablo 11. \%20 YFC katk1lı kil zemin için tabaka cinslerine göre birim maliyetler

\begin{tabular}{|c|c|c|c|}
\hline Poz Numarası & Tanımı ve Birimi & $\begin{array}{c}\text { Birim } \\
\text { Fiyatı (TL) }\end{array}$ & $\begin{array}{l}\mathbf{m}^{2} / \mathbf{c m} \\
\text { Maliyeti } \\
\text { (TL) }\end{array}$ \\
\hline KGM/6405/S-M & $\begin{array}{l}5 \mathrm{~cm} \text { sıkışmış kalınlıkta } 1 \mathrm{~m}^{2} \text { asfalt betonu aşınma } \\
\text { tabakası yapılması, }\left(\mathrm{m}^{2}\right)\end{array}$ & 13,06 & 2,61 \\
\hline KGM/6320 & $\begin{array}{l}\text { Asfalt betonu binder tabakası yapılması (kırılmış ve } \\
\text { elenmiş ocak taşı ile) (ton) Not: Kaplama } \\
\text { yoğunluğu } 2,40 \mathrm{~g} / \mathrm{cm}^{3}\end{array}$ & 83,78 & 2,02 \\
\hline KGM/6212-A & $\begin{array}{l}12 \mathrm{~cm} \text { sıkışmış kalınlıkta } 1 \mathrm{~m}^{2} \text { asfalt betonu bitümlü } \\
\text { sıcak temel tabakası yapılması }\left(\mathrm{m}^{2}\right)\end{array}$ & 21,93 & 1,83 \\
\hline KGM/6100/3 & $\begin{array}{l}\text { Plentmix temel yapılması (kırılmış ve elenmiş ocak } \\
\text { taşı ile) (ton) Not: Kaplama yoğunluğu } 2,40 \mathrm{~g} / \mathrm{cm}^{3}\end{array}$ & 40,49 & 0,97 \\
\hline
\end{tabular}

Bu hesaplamalara göre, \%20 YFC katkılı kil zemin için esnek yol üstyapı kalınlığının $\mathrm{m}^{2} / \mathrm{cm}$ cinsinden birim maliyeti toplam 7,43 TL olarak elde edilmiştir.

$\mathrm{Bu}$ hesaplamalara göre, tabaka kalınlıklarının belirlenmesinde \%20 YFC katkılı kil zemin, saf killi zemine oranla birim maliyeti yaklaşık \%5,65 oranında azaltmaktadır. $1000 \mathrm{~m}$ uzunluğunda ve $20 \mathrm{~m}$ genişliğindeki bölünmüş bir yolda yol taban zemininin \%20YFC ile iyileştirilmesi durumunda 8,400.00 TL tasarruf sağlanmış olacaktır.

\section{Sonuçlar ve Tartışma}

YFC ilave edilerek dayanımı arttırılan killi bir yol taban zemininin, karayolu esnek üstyapı tabaka kalınlıklarına ve maliyetlerine etkilerinin araştırıldığı bu çalışmada aşağıdaki sonuçlar elde edilmiştir;

* Kil zeminin içeriğindeki YFC miktarının artmasına bağlı olarak, karışımların optimum su muhtevalarında artış, maksimum kuru yoğunluk değerlerinde ise azalma görülmüştür. Bu durumun YFC'nin yüksek su emme potansiyeli ve ince taneli yapıya sahip olmasından kaynaklandığı düşünülmektedir.

* Serbest basınç deneyi sonuçlarına göre, YFC ilavesi ile saf zeminin serbest basınç dayanım artmış ve en yüksek dayanım \%20YFC içeren karışımlardan elde edilmiştir. Bu sonuç, kil zeminin kayma direnci ve kohezyon yeteneği üzerinde YFC'nin iyileştirici bir etkiye sahip olduğunu göstermektedir.

* CBR deney sonuçlarına göre, \%20YFC içeren karışımların 2,5 ve 5 mm'lik deplasmanlara karşılık gelen CBR değerleri, saf zeminlere kıyasla sırasıyla 13,0 ve 11,96 kat fazla elde edilmiştir. Bu önemli artışlar, kil zeminin kalıcı deformasyon direnci üzerinde YFC'nin çok olumlu bir etkiye sahip olduğunu göstermektedir.

* Saf ve katkılı zeminler için hesaplanan tabaka kalınlıklarına göre, \%20 YFC içeren killi zeminler için tabaka kalınlığı saf zemine kıyasla \%26,67 oranında büyük bir azalma göstermiştir.

* Maliyet hesabı sonuçlarına göre, \%20 YFC içeren killi zeminler için üstyapı maliyeti, saf kil zemine kıyasla yaklaşık \%5,65 oranında bir azalma göstermiştir.

* Karayolu üstyapı tabakaları için birim maliyetler dikkate alındığında; $1000 \mathrm{~m}$ uzunluğunda ve $20 \mathrm{~m}$ genişliğindeki bölünmüş bir yolun taban zemini \%20 YFC ile iyileştirildiğinde, saf zemine kıyasla esnek üstyapı maliyetinde 8,400.00 TL tasarruf sağlanmış olacaktır.

Sonuç olarak, killi bir zemine YFC ilave edilmesiyle zeminin dayanımının önemli ölçüde arttığı, esnek yol üstyapı tabaka kalınlıklarının ve yapım maliyetlerinin önemli ölçüde azaldığı tespit edilmiştir. Bu sebeple, zeminlerinin YFC ile iyileştirilmesi durumunda yol üstyapı maliyeti ve YFC'nin çevreye verdiği zararı önlemek bakımından çok faydalı olacağı düşünülmektedir.

\section{Teşekkür}

Bu çalışma, İnönü Üniversitesi Bilimsel Araştırma Projeleri (BAP) Koordinasyon Birimi, FDK-2018-1459 numaralı projesi ile desteklenmiştir. 


\section{Kaynaklar}

[1] Tunç A. Yol Malzemeleri ve Uygulamaları. Türkiye, 2001.

[2] Çakılcıoğlu İ. Yüksek Plastisiteli Killerin Stabilizasyonu. Yüksek Lisans Tezi, Sakarya Üniversitesi Fen Bilimleri Enstitüsü, Sakarya; 2007.

[3] Hausman MR. Engineering Principles of Ground Modification. International Edition, 1990; 321-335.

[4] Kılıç G. Çimento İle Zemin Stabilizasyonu. Yüksek Lisans Tezi, Yıldız Teknik Üniversitesi Fen Bilimleri Enstitüsü, İstanbul; 2008.

[5] Emery JJ, Kim CS, Cotsworth RP. Base Stabilization Using Pelletized Blast Furnace Slag, 1976; 4(1):94-100.

[6] Öner A, Yıldırım T. Öğütülmüş Yüksek Fırın Cürufu İçeren ve İçermeyen Betonlarda Kırmataş Kumu İçeriğinin Beton Özeliklerine Etkisi. Deprem Sempozyumu, Kocaeli, 2005.

[7] Tokyay M, Erdoğdu K. Cüruflar ve Cüruflu Çimentolar, Türkiye Çimento Müstahsilleri Birliği, Ankara; 2002.

[8] ACI 233.R-95, Ground Granulated Blast-Furnace Slag As a Cementitious Constituent in Concrete Reported by ACI Committe 233, American Concrete Institude, 2005 Detroit, Michigan.

[9] Bilgen G, Kavak A, Yıldırım ST, Çapar ÖF. Yüksek Fırın Cürufunun İnşaat Sektöründeki Yeri ve Önemi. 2'nci Ulusal Katı Atık Yönetimi Kongresi Bildirileri, 2010. Cilt 1: 506-513, Mersin.

[10] Bilgen G. Yüksek Fırın Cürufu ile Zemin Stabilizasyonu. Yüksek Lisans Tezi, Fen Bilimleri Enstitüsü, Kocaeli; 2007.

[11] Sivrikaya O, Yavascan S, Cecen E. Effects of Ground Granulated Blast-Furnace Slag on the İndex and Compaction Parameters of Clayey Soils. Acta Geotechnica. 2014; 19-27.

[12] Bilgen G, Kavak A, Çapar ÖF. Düşük Plasisiteli Bir Kilde Katkı Olarak Çelikhane Cürufunun Kullanılması ve Kireç İle Etkileşimi. Karaelmas Fen ve Mühendislik Dergisi, 2012; 2(2):30-38.

[13] Cokca E, Yazici V, Ozaydin V. Stabilization of Expansive Clays Using Granulated Blast Furnace Slag (GBFS) and GBFS-Cement. Geotechnical and Geological Engineering, 2009; 27: 489-499.

[14] Karayolları Esnek üstyapılar Projelendirme Rehberi, 2013.

[15] Arulrajah A, Mohammadinia A, Horpibulsuk S, Samingthong W. Influence of Class F Fly Ash and Curing Temperature on Strength Development of Fly Ash Recycled Concrete Aggregate Blends, 2016; Construction and Building Materials, 127:743-750.

[16] Kök BV. Karayolu Mühendisliği ve Tasarımı. Nobel Yayınevi, Ankara, Türkiye, 2019.

[17] American Association of State Highway and Transportation Officials, AASHTO Guide for Design of Pavement Structures. Washington, D.C.:1993.

[18] Kök BV, Yılmaz M, Geçkil A. Çimento Stabilizasyonlu Zeminin Esnek Üstyapı Maliyetine Etkisi. Pamukkale Üniversitesi Mühendislik Bilimleri Dergisi, 2012; Cilt 18, Sayı 3, Sayfa 165-172.

[19] http://www.birimfiyat.net, 2019. 